\title{
OPTIMIZATION OF NUTRITION FACTORS ON CHITINASE PRODUCTION FROM A NEWLY ISOLATED Chitiolyticbacter meiyuanensis SYBC-H1
}

\author{
Zhikui Hao $^{1,2}$; Yujie Cai ${ }^{1}$; Xiangru Liao ${ }^{1} *$; Xiaoli Zhang ${ }^{3}$; Zhiyou Fang ${ }^{4}$; Dabing Zhang ${ }^{5}$
}

${ }^{1}$ The Key Laboratory of Industrial Biotechnology, Ministry of Education, School of Biotechnology, Jiangnan University, Wuxi 214122, People's Republic of China; ${ }^{2}$ Fishery Extension Station of Yingzhou District, 28 Yingzhou Road, Fuyang 236000, Anhui Province, People's Republic of China; ${ }^{3}$ School of Textile Engineering and Art, Anhui Agricultural University, Hefei 230036; ${ }^{4}$ Department of Cell Biology and Cell Dynamics Program, University of Massachusetts Medical School, Worcester, MA 01605, USA; ${ }^{5}$ Jiangsu Hanbon Science \& Technology Co. Ltd, Huai'an, Jiangsu 223001, People's Republic of China.

Submitted: November 20, 2010; Approved: August 30, 2011.

\begin{abstract}
The present study reports statistical medial optimization for chitinase production by a novel bacterial strain isolated from soil recently, which the name Chitinolyticbacter meiyuanensis SYBC-H1 is proposed. A sequential statistical methodology comprising of Plackett-Burman and response surface methodology (RSM) was applied to enhance the fermentative production of chitinase, in which inulin was firstly used as an effective carbon source. As a result, maximum chitinase activity of $5.17 \mathrm{U} / \mathrm{mL}$ was obtained in the optimized medium, which was 15.5-fold higher than that in the basal medium. The triplicate verification experiments were performed under the optimized nutrients levels which indicated that it well agreed with the predicted value.
\end{abstract}

Key words: chitinase, medium optimization, response surface method, inulin, Chitinolyticbacter meiyuanensis SYBC-H1

\section{INTRODUCTION}

Chitin is the second most abundant insoluble biodegradable polymer, which exists naturally in the biosphere as a structural polysaccharide of $\beta$-1,4-N-acetyl-D-glucosamine (16). It is highly distributed in nature, as a constituent of insect exoskeleton, shells of crustaceans, fungal cell walls (11), and algae components (5). More than $1 \times 10^{11}$ tons of chitin are estimated to be produced annually in marine waters alone, mostly by copepods (24). Most of chitin for commercial are come from shrimp shellfish waste.

Chitinase (E.C.3.2.1.14) are enzymes capable of hydrolyzing chitin to its oligo and monomeric components. Microorganisms (5), higher plants (17), even lower animals and birds (3) are known to produce chitinase. Microorganisms are well investigated, Serratia marcescens is the most common and well known microorganism for chitinase production (4).

Recently, chitinase are gaining much attention worldwide

*Corresponding Author. Mailing address: The Key Laboratory of Industrial Biotechnology, Ministry of Education, School of Biotechnology, Jiangnan University, Wuxi 214122, People's Republic of China..; Tel/Fax.: +86 5108532 6880.; E-mail: liaoxiangru@163.com 
$(7,8,12,26)$, because of their wide range of biotechnological applications in such as generation of fungal protoplasts (12), shellfish waste management, production of single cell protein (34), and specially in the production of chitooligosaccharides (immune enhancers), $\quad N$-acetyl-glucosamine, or chitooligosaccharides for various applications (34), and in biocontrol of fungal plant pathogens (6).

In order to industrially convert the complex chitin to simple or proper compounds, much work has been done to improve the production of chitinase by a cheap and energysaving process using genetically modified organisms (18) and/or multistage fermentation system. An enhancing effect of glucose on chitinase production was reported by Bhushan when glucose was used with chitin as carbon source (2). However, a suppressing effect of glucose on chitinase production was reported by Miyashita et al. (23). Therefore, the current challenge is to further enhance the enzyme activity via strain selection and culture conditions optimization.

In the conventional method, the medium is optimized by changing one factor at a time while keeping others at a constant level $(26,33)$, which is laborious and often leads to wrong conclusions (20). Multivariate experiments are designed not only to reduce the number of necessary experiments in the optimization process, but also to produce more defined results than those available by univariate strategies (27). PlackettBurman (P-B) and response-surface methodology (RSM) are multivariate analyzing tools comprising of mathematical and statistical techniques for generating empirical models that obtained importance for optimizing production conditions of industrially high value products such as chemicals, enzymes, and for studying enzyme kinetics. The statistical tool has been used in many biotechnological processes namely optimization of culture conditions (19), enzyme production (32), ethanol production (10), and biomass production (36). It was also useful for optimizing the yield of recombinant products such as actinorhodin (9), nisin (21), lysozyme (14), alkaline protease (1), and hirudin (28) as well as extracellular polysaccharides and biomass (13). However, there have been few studies on chitinase production using (P-B) and RSM (31).

A novel bacterial strain was isolated from soil recently, which named Chitinolyticbacter meiyuanensis SYBC-H1. In this paper, the effect of the addition of inulin to the liquid culture of the strain was investigated, and RSM, an efficient experimental strategy, was applied in optimizing the medial composition to improve the production of chitinase.

\section{MATERIALS AND METHODS}

\section{Microorganism}

The chitinase-producing bacterium was isolated in our laboratory from the soil samples collected from Meiyuan Park $\left(33^{\circ} 56^{\prime} \mathrm{N}, 120^{\circ} 18^{\prime} \mathrm{E}\right)$, Wuxi city, China. The physiological and biochemical tests of the isolated chitinase-producing strain were done as described in Bergey's manual of systematic bacteriology (15). The strain was further identified according to $16 \mathrm{~S}$ rRNA studies. The obtained sequence was searched against the GenBank database and homology studies were undertaken to identify the isolate. Initially sequence was analyzed at National Center for Biotechnology Information (NCBI) server (http://www.ncbi.nlm.nih.gov). Nearly complete $16 \mathrm{~S}$ rRNA gene sequence of the isolate, consisting of 1,526 nucleotides, was determined and deposited in the DDBJ/ GenBank/ EMBL database under the accession number of GQ981314. Homology search indicated that the strain SYB-H1 had sequence identity of $95.0 \%$ to $\mathrm{SAY}_{3}{ }^{\mathrm{T}}(\mathrm{AB}$ 453176) as closest relative (30). On the basis of physiological, biochemical and 16S rRNA gene sequence study, the isolate was identified as gen. nov., sp. nov. (22) and named Chitinolyticbacter meiyuanensis SYBC-H1, which was deposited into the China General Microbiological Culture Collection Center (CGMCC3438) and American Type Culture Collection (ATCC BAA-2140). The strain was first studied on fermentation.

\section{Preparation of seed culture}

The stock culture was maintained on nutrient agar slants kept at 
$4{ }^{\circ} \mathrm{C}$. The seed culture was prepared by inoculating single colony in a plate containing the medium composed of $(\mathrm{g} / \mathrm{L}) 2.0$ glucose, 4.0 peptone, $0.7 \mathrm{KH}_{2} \mathrm{PO}_{4}, 0.5 \mathrm{MgSO}_{4} \cdot 7 \mathrm{H}_{2} \mathrm{O}, 0.3$ $\mathrm{K}_{2} \mathrm{HPO}_{4}, 0.02 \mathrm{FeSO}_{4} \cdot 7 \mathrm{H}_{2} \mathrm{O}$, and 20.0 agar. In order to have stable strains, the cells were transferred into a fresh medium for several times. After incubated for 2 days at $30{ }^{\circ} \mathrm{C}$, a loop full of the colony from the flat plate is transferred to $50 \mathrm{~mL}$ seed medium composed of $(\mathrm{g} / \mathrm{L}) 2.0$ glucose, 4.0 peptone, 0.7 $\mathrm{KH}_{2} \mathrm{PO}_{4}, 0.5 \mathrm{MgSO}_{4} \cdot 7 \mathrm{H}_{2} \mathrm{O}, 0.3 \mathrm{~K}_{2} \mathrm{HPO}_{4}$ and $0.02 \mathrm{FeSO}_{4} \cdot 7 \mathrm{H}_{2} \mathrm{O}$ in $250 \mathrm{~mL}$ shake flasks and incubated at $30^{\circ} \mathrm{C}$ for 12 hour on a rotary shaker $(200 \mathrm{rpm})$. The cells growth was monitored by absorbance measurement at $600 \mathrm{~nm}$ with a UV-visible spectrophotometer. For shake flask culture, the liquid medium was sterilized in the autoclave at $121^{\circ} \mathrm{C}$ for $20 \mathrm{~min}$, and $\mathrm{pH}$ was adjusted to 7.0 before autoclaving.

\section{Culture conditions}

Chitinase production was carried out by shake-flask culture. Medium were determined according to the result of the Plackett-Burman factorial and the Response Surface Method design. The $\mathrm{pH}$ was adjusted to 6.5 before autoclaving at $121{ }^{\circ} \mathrm{C}$ for $20 \mathrm{~min}$. Subsequently, inoculated with $4 \%$ (w/w) seed and incubated at $30{ }^{\circ} \mathrm{C}$ for $72 \mathrm{~h}$ under shaking at $200 \mathrm{rpm}$. The broth was centrifuged at $10,000 \times g$ for $10 \mathrm{~min}$ at $4{ }^{\circ} \mathrm{C}$, and the supernatant was used for chitinase assay.

\section{Effect of incubation period on the chitinase production}

Flasks containing $50 \mathrm{ml}$ of production medium were inoculated with $4.0 \%$ seed culture and incubated at $30{ }^{\circ} \mathrm{C}$ with constant shaking at $200 \mathrm{rpm}$. Following incubation for $12 \mathrm{~h}$ intervals, fermentation broth was centrifuged and chitinase activity was determined.

\section{Assay of chitinase activity}

The chitinase activity was measured by reduction of 3,5dinitrosalicylic acid, in the presence of the aminosugar $\mathrm{N}$ acetyl-D-glucosamine (NAG) released by enzymatic hydrolysis of colloid chitin according to the method described by RojasAvelizapa et al. (29). The absorbance was recorded at $530 \mathrm{~nm}$. Readings were compared with a standard curve prepared with a series of dilutions of NAG (0-5.0 $\mathrm{mmol} / \mathrm{mL})$ and 3, 5dinitrosalicylic acids. The chitinase activity was assayed in triplicate and the average enzyme activity with standard deviations was measured using software of SPSS 11.5. One unit chitinase activity (U) was defined as the amount of enzyme required for producing $1 \mathrm{mmol}$ of $\mathrm{NAG}$ at $37{ }^{\circ} \mathrm{C}$ in 1 minute.

\section{Screening of critical media components using a Plackett-}

\section{Burman design}

The Plackett-Burman factorial design was used to select significant medium components affecting the production of chitinase. Previous studies showed that peptone, urea, corn steep liquor powder, ammonium sulfate, glucose, inulin, starch, sodium sulfate, fructose, and Magnesium sulfate were effective medial components for process modeling. A total of fourteen process variables comprising of ten medial components (peptone, urea, corn steep liquor powder, ammonium sulfate, glucose, inulin, starch, sodium sulfate, fructose, and Magnesium sulfate) and one dummy variable were studied in Plackett-Burman screening experiments. Each variable was represented at 3 levels, upper ('high, +'), intermediate ('center point, 0') and lower ('low, -') levels of the range covered by each variable and the response (Tables 1 and 2). Experimental responses were analyzed by first order model by the following equation $\mathrm{Y}=\beta \mathrm{o}+\Sigma \beta \mathrm{i} x_{i}$ where $\mathrm{Y}$ is the response for chitinase production, $\beta_{o}$ is the model intercept and $\beta_{i}$ is the linear coefficient, and $x_{i}$ is the level of the independent variable. According to the Stat-Ease analysis, a first-order model could be obtained from the regression results of fractional factorial experiment. This model describes the interaction among factors and it is used to screen and evaluate important factors that influence the response. From the regression analysis of the variables, the factors having significant effect on chitinase 
production were further optimized by RSM.

\section{Optimization of medium with the Response Surface Method}

Inulin, urea, and sodium sulfate were identified as the key factors that influenced chitinase production from the above experiments (Table 3), and their suitable concentration ranges were also preliminarily determined. Consequently, RSM was employed to optimize the four most significant factors, namely inulin, urea, sodium sulfate, and chitin powder (particle size < $100 \mathrm{mesh}$ ), which had been screened by fractional factorial design for chitinase production enhancement based on central composite design. The four independent factors were studied at five different levels $(-1.41,-1,0,+1$, and +1.41$)$ as shown in Table 4. The factors were coded according to Eq. 1:

$$
\mathrm{X}_{\mathrm{i}}=\left(\mathrm{X}_{\mathrm{i}}-\mathrm{X}_{0}\right) / \Delta \mathrm{X}_{\mathrm{i}}, \mathrm{i}=1,2, . ., \mathrm{k}
$$

Where $X i$ and $x i$ are the actual value and codified value, respectively. $X_{0}$ is the value of $X i$ at center point, and $\triangle X i$ is the step change value. The second-order model used to fit the response to the independent variables is shown in Eq. 2:

$$
Y=\beta_{0}+\sum \beta_{i} x_{i}+\sum \beta_{i} x^{2}+\sum \beta_{i j} x_{i} x_{j}, i=1,2, \ldots, k
$$

Where $\mathrm{Y}$ is the predicted response, $x_{i}$ and $x_{j}$ are the coded independent factors that influence the response variable $\mathrm{Y}, \beta_{o}$ is the intercept, $\beta_{i}$ represents the linear effect of $x_{i}, \beta_{i j}$ represents the interaction between $x_{i}$ and $x_{j}$, and $\beta_{i j}$ represents the quadratic effect of $x_{i}$. Design Expert version 7.1.5 statistical software (Stat-Ease, Minneapolis, MN) was used for the experimental design and regression analysis of the experimental data. Statistical analysis of the model was performed to evaluate the analysis of variance (ANOVA). The quality of the polynomial model equation was judged statistically by the coefficient of determination $\mathrm{R}^{2}$, and its statistical significance was determined by an $\mathrm{F}$ test. The significance of the regression coefficients was tested by $\mathrm{t}$ test.

\section{RESULTS}

\section{Screening of significant factors by Plackett-Burman design}

In the Plackett-Burman model, 14 experiments were required tests to screen the importance of eleven medium components derived from single-factor optimization (Tables 1 and 2). The values of Prob $>\mathrm{F}$ less than 0.05 implied that model terms were significant. From the experimental data, all of these variables could distinctly affect the production of chitinase (Table 3). Among them, Corn steep liquor powder, glucose, starch, and magnesium sulfate exerted negative effect, whereas the other six variables exerted positive effects on the production of chitinase. The optimum variables (urea, inulin, and sodium sulfate) were further evaluated by a response surface methodology (RSM) design.

Table 1. Variables representing medium components used in Plackett-Burman design

\begin{tabular}{clccc}
\hline Variables & \multicolumn{1}{c}{$\begin{array}{c}\text { Medium } \\
\text { component }\end{array}$} & $\begin{array}{c}\text { values } \\
(\mathbf{g} / \mathbf{L})\end{array}$ & $\begin{array}{c}\text { 0 values } \\
(\mathbf{g} / \mathbf{L})\end{array}$ & $\begin{array}{c}\text { values } \\
(\mathbf{g} / \mathbf{L})\end{array}$ \\
\hline $\mathrm{X}_{1}$ & Peptone & $5.00(+)$ & 3.00 & $1.00(-)$ \\
$\mathrm{X}_{2}$ & Urea & $1.30(+)$ & 0.78 & $0.26(-)$ \\
$\mathrm{X}_{3}$ & Corn steep powder & $1.33(+)$ & 0.80 & $0.27(-)$ \\
$\mathrm{X}_{4}$ & Ammonium sulfate & $2.86(+)$ & 1.72 & $0.57(-)$ \\
$\mathrm{X}_{5}$ & Glucose & $2.00(+)$ & 1.20 & $0.40(-)$ \\
$\mathrm{X}_{6}$ & Inulin & $1.16(+)$ & 0.70 & $0.23(+)$ \\
$\mathrm{X}_{7}$ & Starch & $1.95(+)$ & 1.17 & $0.39(-)$ \\
$\mathrm{X}_{8}$ & Magnesium sulfate & $0.492(+)$ & 0.30 & $0.098(-)$ \\
$\mathrm{X}_{9}$ & Fructose & $2.00(+)$ & 1.20 & $0.40(-)$ \\
$\mathrm{X}_{10}$ & Sodium sulfate & $0.284(+)$ & 0.17 & $0.057(-)$ \\
\hline $\mathrm{X}_{1-}$ & & & \\
\hline
\end{tabular}

$\mathrm{X}_{1}-\mathrm{X}_{10}$ represent different assigned variables (Peptone, Urea, Corn steep liquor powder, Ammonium sulfate, Glucose, Inulin, Starch, Magnesium sulfate, Fructose, Sodium sulfate); the sign ' + ' is for high concentration of variables, ' 0 ' is for intermediate concentration of variables and '- ' is for low concentration of variables. 
Table 2. Plackett-Burman experimental design matrix with the observed response (Chitinase activity). The values showed in the table were averaged from two independent triplicate experiments with means less than $5 \%$.

\begin{tabular}{|c|c|c|c|c|c|c|c|c|c|c|c|c|}
\hline \multirow[b]{2}{*}{ Run } & \multicolumn{11}{|c|}{ Variables } & \multirow{2}{*}{$\begin{array}{c}\text { Chitinase } \\
\text { (U/ml) }\end{array}$} \\
\hline & $\mathrm{X}_{1}$ & $\mathbf{X}_{2}$ & $X_{3}$ & $\mathbf{X}_{4}$ & $X_{5}$ & $X_{6}$ & $\mathbf{X}_{7}$ & $\mathbf{X}_{8}$ & $X_{9}$ & $X_{10}$ & D & \\
\hline 1 & -1 & 1 & 1 & 1 & -1 & -1 & -1 & 1 & -1 & 1 & 1 & 0.79 \\
\hline 2 & -1 & -1 & 1 & -1 & 1 & 1 & -1 & 1 & 1 & 1 & -1 & 0.88 \\
\hline 3 & 1 & -1 & 1 & 1 & -1 & 1 & 1 & 1 & -1 & -1 & -1 & 0.70 \\
\hline 4 & 0 & 0 & 0 & 0 & 0 & 0 & 0 & 0 & 0 & 0 & 0 & 0.93 \\
\hline 5 & 1 & 1 & -1 & -1 & -1 & 1 & -1 & 1 & 1 & -1 & 1 & 1.26 \\
\hline 6 & -1 & -1 & -1 & -1 & -1 & -1 & -1 & -1 & -1 & -1 & -1 & 0.75 \\
\hline 7 & 1 & -1 & -1 & -1 & 1 & -1 & 1 & 1 & -1 & 1 & 1 & 0.41 \\
\hline 8 & 1 & 1 & -1 & 1 & 1 & 1 & -1 & -1 & -1 & 1 & -1 & 1.27 \\
\hline 9 & -1 & -1 & -1 & 1 & -1 & 1 & 1 & -1 & 1 & 1 & 1 & 1.32 \\
\hline 10 & -1 & 1 & 1 & -1 & 1 & 1 & 1 & -1 & -1 & -1 & 1 & 0.72 \\
\hline 11 & 0 & 0 & 0 & 0 & 0 & 0 & 0 & 0 & 0 & 0 & 0 & 0.89 \\
\hline 12 & -1 & 1 & -1 & 1 & 1 & -1 & 1 & 1 & 1 & -1 & -1 & 0.84 \\
\hline 13 & 1 & 1 & 1 & -1 & -1 & -1 & 1 & -1 & 1 & 1 & -1 & 1.11 \\
\hline 14 & 1 & -1 & 1 & 1 & 1 & -1 & -1 & -1 & 1 & -1 & 1 & 0.98 \\
\hline
\end{tabular}

$\mathrm{X}_{1}-\mathrm{X}_{10}$ represent different assigned variables(Peptone, Urea, Corn steep liquor powder, Ammonium sulfate, Glucose, Inulin, Starch, Magnesium sulfate, Fructose, Sodium sulfate), and D are the unassigned/dummy variable; the sign ' + ' is for high concentration of variables, the sign ' 0 ' is for middle concentration of variables and '- ' is for low concentration of variables.

Table 3. Statistical analysis of medium components for chitinase production by Plackett-Burman design.

\begin{tabular}{|c|c|c|c|c|c|c|c|}
\hline Source & $\begin{array}{c}\text { Medium } \\
\text { component }\end{array}$ & $\begin{array}{c}\text { Sum of } \\
\text { squares }\end{array}$ & $\begin{array}{c}\text { Coefficient } \\
\text { estimate }\end{array}$ & $\begin{array}{c}\text { Mean } \\
\text { square }\end{array}$ & $\begin{array}{l}\text { Stdized } \\
\text { Effects }\end{array}$ & F-value & $\begin{array}{c}P \text {-value } \\
\text { Prob }>\text { F }\end{array}$ \\
\hline Model & & 0.89 & 0.91 & 0.089 & & 204.12 & 0.0049 \\
\hline $\mathrm{X}_{1}$ & Peptone & 0.009 & 0.028 & 0.009 & 0.055 & 20.74 & 0.0450 \\
\hline $\mathrm{X}_{2}$ & Urea & 0.092 & 0.088 & 0.092 & 0.18 & 210.00 & 0.0047 \\
\hline$X_{3}$ & Corn steep liquor powder & 0.049 & -0.064 & 0.049 & -0.13 & 112.93 & 0.0087 \\
\hline$X_{4}$ & Ammonium sulfate & 0.037 & 0.056 & 0.037 & 0.11 & 85.5 & 0.0115 \\
\hline$X_{5}$ & Glucose & 0.044 & -0.061 & 0.044 & -0.12 & 101.50 & 0.0097 \\
\hline $\mathrm{X}_{6}$ & Inulin & 0.11 & 0.098 & 0.11 & 0.20 & 260.74 & 0.0038 \\
\hline $\mathrm{X}_{7}$ & Starch & 0.072 & -0.078 & 0.072 & -0.16 & 164.74 & 0.0060 \\
\hline $\mathrm{X}_{8}$ & sodium sulfate & 0.16 & -0.11 & 0.16 & -0.23 & 357.50 & 0.0028 \\
\hline $\mathrm{X}_{9}$ & Fructose & 0.29 & 0.15 & 0.29 & 0.31 & 651.90 & 0.0015 \\
\hline $\mathrm{X}_{10}$ & Magnesium sulfate & 0.033 & 0.053 & 0.033 & 0.11 & 75.6 & 0.0130 \\
\hline
\end{tabular}

$\mathrm{X}_{1}-\mathrm{X}_{10}$ represent different assigned variables(Peptone, Urea, Corn steep liquor powder, Ammonium sulfate, Glucose, Inulin, Starch,

Magnesium sulfate, Fructose, Sodium sulfate)

Std. Dev. = 0.021; R-Squared =0.999; Mean =0.91; Adj R-Squared =0.9941;

C.V. $\%=2.30 ;$ Pred R-Squared $=0.9843 ;$ PRESS $=0.014 ;$ Adeq Precision $=46.992$

\section{Optimization using RSM}

To search for the optimum combination of these components in the culture medium, a CCD experimental plan was carried out. Their suitable concentrations ranges were preliminarily determined. Table 4 shows various combinations used and the corresponding chitinase yield. Data were analyzed by linear multiple regression using the Design-Expert (Version 7.0; Stat-Ease, Inc.) and the following equation was obtained.

$Y=4.68+0.34 X_{1}+0.25 X_{2}+0.52 X_{3}+0.16 X_{4}+0.041 X_{1} X_{2}+0.025 X_{1} X_{3}-0.19 X_{1} X_{4}$
$-0.11 X_{2} X_{3}+0.19 X_{2} X_{4}+0.39 X_{3} X_{4}-0.95 X_{1}^{2}-0.32 X_{2}^{2}-0.53 X_{3}{ }^{2}-0.16 X_{4}{ }^{2}$

Where $\mathrm{X}_{1}, \mathrm{X}_{2}, \mathrm{X}_{3}$ and $\mathrm{X}_{4}$ are the symbols of concentration of inulin, urea, chitin and sodium sulfate, respectively. The experimental results revealed that this mathematical tool could satisfactorily explain the effects of the variables concentration (inulin, urea, chitin, and Sodium Sulfate) in chitinase production of Chitinolyticbacter meiyuanensis SYBC-H1 in shake-flask cultures. Analysis of variance (ANOVA) for the Quadratic model were shown in Table 5. Value of "Model 
Prob $>$ F', less than 0.0060 implied that the model was high significant. In this case $\mathrm{X}_{1}, \mathrm{X}_{3}, \mathrm{X}_{1}{ }^{2}$ and $\mathrm{X}_{3}{ }^{2}$ are significant model terms. The "Lack of Fit Prob $>F$ value" of 0.335 showed that the lack of fit is insignificant. The $\mathrm{R}^{2}$ coefficient obtained, of 0.8422 , suggests that it is a reliable model and that $84.22 \%$ of the sample variation of chitinase yield is attributed to a high correlation between the independent variables. Only $15.78 \%$ of the total variation of chitinase production was not explained by the model. The relatively high-adjusted determination coefficient $\left(\mathrm{R}^{2}{ }_{\text {Adj }}=0.6582\right)$ accounts for significance of the model. The coefficient of variation $(\mathrm{CV})$ indicated the degree of precision with which the calculations were compared. Usually, a high $\mathrm{CV}$ value represents low reliability of the experiment. The low value obtained $(\mathrm{CV}=25.76 \%)$ showed a small residual variability data and the greater reliability of the experiments performed. The observed chitinase activity (the response) versus those factors from the empirical model equation 2 was shown in Figure 1, which indicated that the predicted data of the response from the empirical model was in agreement with the observed ones in the range of the operating variables. The graphical representation provides a method to visualize the relationship between the response and experimental levels of each variable and the type of interactions between test variables to deduce the optimum conditions. In this design, the response surface curves for the four variables were shown in Figure 2. The response surface representing chitinase was a function of concentrations of the two medium components with another nutrient being at a zero level. The regression equation, maximized by the Design Expert 7.0 (Minneapolis, USA) software, allowed to obtain the following optimal coded units for test variables: $\mathrm{X}_{1}=0.1, \mathrm{X}_{2}=0.55, \mathrm{X}_{3}=$ 0.80 and $\mathrm{X}_{4}=1.00$, which corresponded to optimal concentrations of $(\mathrm{g} / \mathrm{L}) 3.10$ urea, 3.55 inulin, 3.80 chitin and 0.64 sodium sulfate, for the maximal chitinase activity of the $5.17 \mathrm{U} / \mathrm{mL}$, predicted by the mathematical model with a high model accuracy. The $\mathrm{P}$ values are used for checking the significance of each coefficient which, in turn, it is necessary to understand the pattern of the mutual interactions between the important variables, and the small magnitude of $\mathrm{P}$ values means that the corresponding coefficients are more significant. A positive coefficient represents an effect that favors the optimization of chitinase yield, while a negative value indicates an antagonistic effect.

Table 4. Experimental design and results of the central composite design. The values showed in the table were averaged from two independent triplicate experiments with means less than $5 \%$.

\begin{tabular}{|c|c|c|c|c|c|c|c|c|c|}
\hline \multirow[b]{3}{*}{ Trial } & \multicolumn{8}{|c|}{ Variables/levels } & \multirow{2}{*}{$\begin{array}{c}\text { Chitinase } \\
(\mathrm{U} / \mathrm{ml})\end{array}$} \\
\hline & \multicolumn{2}{|c|}{ Inulin } & \multicolumn{2}{|l|}{ Urea } & \multicolumn{2}{|l|}{ Chitin } & \multicolumn{2}{|c|}{ sodium sulfate } & \\
\hline & $\begin{array}{c}\text { Coded } \\
\text { value }\end{array}$ & $\begin{array}{l}\text { Actual value } \\
(\mathrm{g} / \mathrm{L})\end{array}$ & $\begin{array}{l}\text { Coded } \\
\text { value }\end{array}$ & $\begin{array}{l}\text { Actual value } \\
(\mathrm{g} / \mathrm{L})\end{array}$ & $\begin{array}{c}\text { Coded } \\
\text { value }\end{array}$ & $\begin{array}{l}\text { Actual value } \\
(\mathrm{g} / \mathrm{L})\end{array}$ & $\begin{array}{l}\text { Coded } \\
\text { value }\end{array}$ & $\begin{array}{l}\text { Actual value } \\
(\mathrm{mM})\end{array}$ & Experimental \\
\hline 1 & -1 & 2 & -1 & 2 & -1 & 2 & -1 & 1 & 1.41 \\
\hline 2 & 0 & 3 & $-\alpha$ & 1.59 & 0 & 3 & 0 & 2 & 3.13 \\
\hline 3 & -1 & 2 & 1 & 4 & -1 & 2 & 1 & 3 & 1.63 \\
\hline 4 & 1 & 4 & -1 & 2 & 1 & 4 & -1 & 1 & 2.92 \\
\hline 5 & 0 & 3 & 0 & 3 & 0 & 3 & 0 & 2 & 4.51 \\
\hline 6 & -1 & 2 & -1 & 2 & 1 & 4 & 1 & 3 & 3.01 \\
\hline 7 & $+\alpha$ & 4.41 & 0 & 3 & 0 & 3 & 0 & 2 & 1.59 \\
\hline 8 & 1 & 4 & 1 & 4 & -1 & 2 & 1 & 3 & 3.73 \\
\hline 9 & 1 & 4 & -1 & 2 & -1 & 2 & 1 & 3 & 0.83 \\
\hline 10 & -1 & 2 & -1 & 2 & 1 & 4 & -1 & 1 & 1.50 \\
\hline 11 & 1 & 4 & 1 & 4 & 1 & 4 & 1 & 3 & 3.63 \\
\hline 12 & 0 & 3 & 0 & 3 & $-\alpha$ & 1.59 & 0 & 2 & 1.35 \\
\hline 13 & 0 & 3 & $+\alpha$ & 4.41 & 0 & 3 & 0 & 2 & 4.41 \\
\hline 14 & 0 & 3 & 0 & 3 & $+\alpha$ & 4.41 & 0 & 2 & 4.51 \\
\hline 15 & 0 & 3 & 0 & 3 & 0 & 3 & $+\alpha$ & 3.41 & 4.44 \\
\hline 16 & -1 & 2 & 1 & 4 & 1 & 4 & -1 & 1 & 1.64 \\
\hline 17 & -1 & 2 & 1 & 4 & -1 & 2 & -1 & 1 & 2.18 \\
\hline 18 & -1 & 2 & -1 & 2 & -1 & 2 & 1 & 3 & 1.80 \\
\hline 19 & 0 & 3 & 0 & 3 & 0 & 3 & 0 & 2 & 4.73 \\
\hline 20 & 1 & 4 & 1 & 4 & -1 & 2 & -1 & 1 & 2.43 \\
\hline 21 & -1 & 2 & 1 & 4 & 1 & 4 & 1 & 3 & 3.70 \\
\hline 22 & $-\alpha$ & 1.59 & 0 & 3 & 0 & 3 & 0 & 2 & 0.91 \\
\hline 23 & 1 & 4 & 1 & 4 & 1 & 4 & -1 & 1 & 3.11 \\
\hline 24 & 0 & 3 & 0 & 3 & 0 & 3 & $-\alpha$ & 0.59 & 4.36 \\
\hline 25 & 1 & 4 & -1 & 2 & 1 & 4 & 1 & 3 & 3.82 \\
\hline 26 & 1 & 4 & -1 & 2 & -1 & 2 & -1 & 1 & 3.25 \\
\hline 27 & 0 & 3 & 0 & 3 & 0 & 3 & 0 & 2 & 4.80 \\
\hline
\end{tabular}


Table 5. Analysis of variance (ANOVA) for the Quadratic model

\begin{tabular}{lcccccc}
\hline Source & $\boldsymbol{d} \boldsymbol{f}$ & $\begin{array}{c}\text { Coefficient } \\
\text { Estimate }\end{array}$ & $\begin{array}{c}\text { Sum } \\
\text { squares }\end{array}$ & $\begin{array}{c}\text { Mean } \\
\text { square }\end{array}$ & F ratio & $\begin{array}{c}\text { Prob. } \\
\text { level }\end{array}$ \\
\hline model & 14 & 4.68 & 36.67 & 2.62 & 4.58 & 0.0060 \\
$\mathrm{X}_{1}$ Inulin & 1 & 0.34 & 2.80 & 2.80 & 4.89 & 0.0472 \\
$\mathrm{X}_{2}$ Urea & 1 & 0.25 & 1.54 & 1.54 & 2.70 & 0.1265 \\
$\mathrm{X}_{3}$-Chitin & 1 & 0.52 & 6.40 & 6.40 & 11.18 & 0.0059 \\
$\mathrm{X}_{4}$-sodium sulfate & 1 & 0.16 & 0.62 & 0.62 & 1.08 & 0.3191 \\
$\mathrm{X}_{1} \times \mathrm{X}_{2}$ & 1 & 0.041 & 0.026 & 0.026 & 0.046 & 0.8338 \\
$\mathrm{X}_{1} \times \mathrm{X}_{3}$ & 1 & 0.025 & 9.851 & 9.851 & 0.017 & 0.8978 \\
$\mathrm{X}_{1} \times \mathrm{X}_{4}$ & 1 & -0.19 & 0.60 & 0.60 & 1.05 & 0.3251 \\
$\mathrm{X}_{2} \times \mathrm{X}_{3}$ & 1 & -0.11 & 0.21 & 0.21 & 0.37 & 0.5547 \\
$\mathrm{X}_{2} \times \mathrm{X}_{4}$ & 1 & 0.19 & 0.55 & 0.55 & 0.96 & 0.3469 \\
$\mathrm{X}_{3} \times \mathrm{X}_{4}$ & 1 & 0.39 & 2.45 & 2.45 & 4.28 & 0.0607 \\
$\mathrm{X}_{1}{ }^{2}$ & 1 & -0.95 & 19.25 & 19.25 & 33.62 & 0.0001 \\
$\mathrm{X}_{2}{ }^{2}$ & 1 & -0.32 & 2.19 & 2.19 & 3.82 & 0.0742 \\
$\mathrm{X}_{3}{ }^{2}$ & 1 & -0.53 & 6.01 & 6.01 & 10.05 & 0.0071 \\
$\mathrm{X}_{4}{ }^{2}$ & 1 & -0.16 & 0.56 & 0.56 & 0.98 & 0.3427 \\
Residual & 12 & & 6.87 & 0.57 & & \\
Lack of fit & 10 & & 8.82 & 0.68 & 29.20 & 0.335 \\
Total error & 2 & & 0.047 & 0.023 & & \\
Corrected total & 26 & & 43.54 & & & \\
\hline
\end{tabular}

R-Squared $=0.8422$, Adj R-Squared $=0.6582$, C.V. $=25.76 \%$,

Adeq Precision ratio $=7.948$

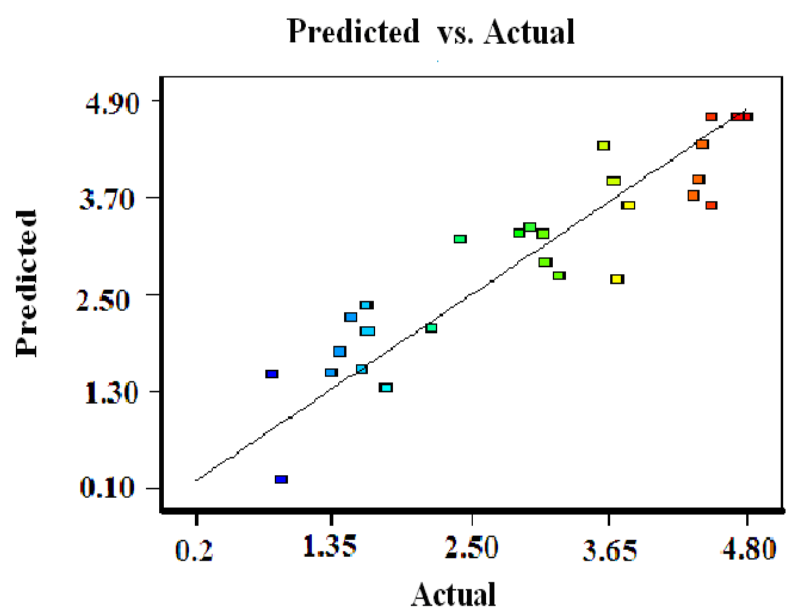

Figure 1. Plot of predicted vs actual chitinase activity (U/mL values)(different color represents the corresponding chitinase activity in the figure).

The regression equation was represented in 3-D response surface plots, and each contour curve corresponds to an infinite number of combinations between two test variables, while the third was maintained at their zero level. The chitinase for different concentrations of the variables could also be predicated from the respective response surface plots (Figure 2 ). The maximum predicted yield was indicated by the surface confined in the response surface diagram.

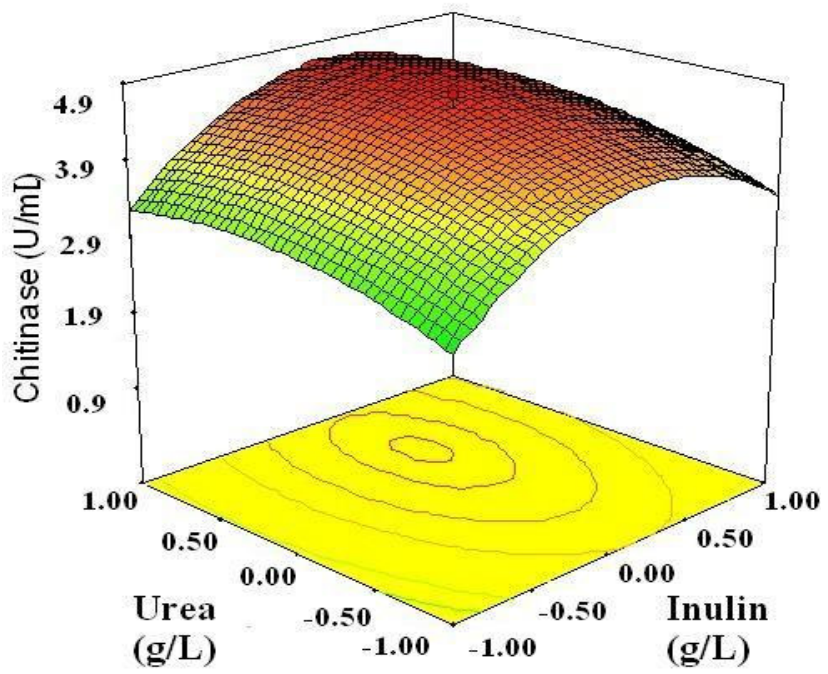

Figure 2. 3D response surface curve for effects of Inulin, Urea and their mutual interaction on chitinase production by SYBC-H1. Other variables held at their zero level. 
Fermentation time courses under optimized and nonoptimized conditions were given in Figure 3. Both time courses showed disparity fermentation process trend. Initially, chitinase yield was very low, and after a lag phase of near 48 hours, chitinase yield gradually increased. After about 84 hours of incubation, chitinase reached the maximum yield. The time course showed that the optimized fermentation conditions change the chitinase producing process. After the enzyme activity reached maximum, the production of chitinase reduced rapidly, which was similar to the previous reports $(26,33)$. The reduction of chitinase might be caused by proteinase degradation or inactivation of the chitinase by unclear mechanisms. In many submerged fermentation processes, when the products reached the highest yield, further increase in incubation time could decrease the yield due to the degradation of metabolites.

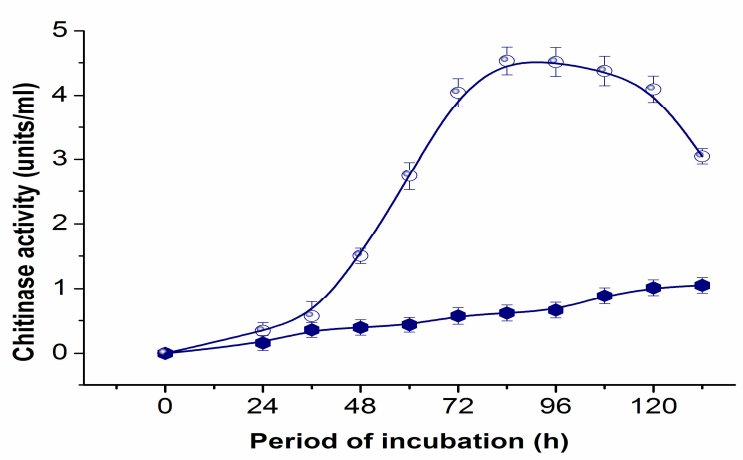

Figure 3. The time-course of chitinase production by SYBC-H1 before and after the optimization $(\bullet$ : Original, $\circ$ : Optimum medium).

Table 6. Effect of medium composition on chitinase production

\begin{tabular}{lcc}
\hline Factors & Original & Optimum medium \\
\hline Urea $(\mathrm{g} / \mathrm{L})$ & - & 3.10 \\
Inulin $(\mathrm{g} / \mathrm{L})$ & - & 3.55 \\
Chitin $(\mathrm{g} / \mathrm{L})$ & 1.00 & 3.80 \\
Sodium sulfate $(\mathrm{g} / \mathrm{L})$ & - & 0.64 \\
Glucose $(\mathrm{g} / \mathrm{L})$ & 1.20 & - \\
Yeast extract(g/L) & 4.00 & - \\
Mineral medium & $*$ & $*$ \\
Chitinase(U/ml) & $0.49 \pm 0.2$ & $5.17 \pm 0.4$ \\
\hline *mineral medium(g/l): $\mathrm{K}_{2} \mathrm{HPO}_{4} 0.7 ; \mathrm{KH}_{2} \mathrm{PO}_{4} ; \mathrm{MgSO}_{4} \cdot 7 \mathrm{H}_{2} \mathrm{O} 0.5 ; \mathrm{FeSO}_{4} \cdot 7 \mathrm{H}_{2} \mathrm{O}$ \\
0.2
\end{tabular}

\section{Optimization and Model Verification}

From the study of plots, the maximum production of chitinase was obtained when the concentration $(\mathrm{g} / \mathrm{L})$ of 3.1 urea, 3.55 inulin, 3.8 chitin, 0.64 sodium sulfate, $0.7 \mathrm{KH}_{2} \mathrm{PO}_{4}$, $0.5 \mathrm{MgSO}_{4} \cdot 7 \mathrm{H}_{2} \mathrm{O}, 0.02 \mathrm{FeSO}_{4} \cdot 7 \mathrm{H}_{2} \mathrm{O}$, and $0.3 \mathrm{~K}_{2} \mathrm{HPO}_{4}($ Table 6) were used for flask fermentation at $30{ }^{\circ} \mathrm{C}$ for $96 \mathrm{~h}$. The maximum value of chitinase yield predicted from this model was $5.17 \mathrm{U} / \mathrm{mL}$. To verify the predicted results, the triplicate verification experiments were performed under the optimized nutrients levels. The mean value of the chitinase activity was $5.16 \pm 0.15 \mathrm{U} / \mathrm{mL}$, which was well agreed with the predicted value $(5.17 \mathrm{U} / \mathrm{mL})$. As a result, the models developed were considered to be accurate and reliable for predicting the production of chitinase by Chitinolyticbacter meiyuanensis SYBC-H1.

\section{DISCUSSION}

Chitin is usually thought as a kind of renewable polysaccharides and organic nitrogenous substance that only second respectively to cellulose and protein in abundance (11). From further study more and more unique properties are being discovered. Chitin, especially its derivatives, are of interest to people due to their diverse applications. However, chitin is insoluble in aqueous solutions and therefore can not be utilized directly. Chitin is currently tapped with acid hydrolysis which incurs some negative effects, e.g. being difficult to control and giving rise to environmental problems. Chitinases hydrolyze chitin is the future direction of research. So far chitinase can be found everywhere in a variety of microorganisms, nevertheless the production level is far from being enough for commercialization. For that reason, isolating novel chitinaseproducing microorganisms and production optimization for high productivity are of great importance to the industry. A strain with strong chitinolytic activity was isolated in our laboratory from the soil samples named Chitinolyticbacter meiyuanensis SYBC-H1 which is gen. nov., sp. nov. The traditional one factor at a time process requires a complete 
series of experiments for important factors of interest, which is laborious and time consuming. Furthermore, such methods could not provide information for the interactions of the factors. Statistical methodology could locate the most important factors levels with minimum effort and time; moreover, it could reveal the interaction among the factor. In this study, a sequential statistical methodology comprising of Plackett-Burman and response surface methodology were applied to enhance the fermentative production of chitinase. A quadratic polynomial equation suggested by the RSM model was then validated experientially. The synthesis of extracellular enzymes such as chitinase depends on carbon and nitrogen. The composition of culture medium has been optimized before, in which glucose principally serves as carbon source (35). In the research, urea, inulin, chitin powder and sodium sulfate were found to be significant factors controlling chitinase yield. This is the first report suggesting a whole new carbon source to produce chitinase through employment of inulin as substrate. Inulin, a D-fructose polymer terminated by glucose residue, makes up $80 \%$ or so of the dry matter of Jerusalem artichoke tubers, and for many years it has been proposed to be a possible feedstock for ethanol production (25). As demonstrated in this paper, Inulin can also be used as an effective carbon source to chitinase yield with much lower cost in substrate.

The study using RSM based on CCD established an efficient model to describe the process. During the process of chitinase production, chitin acts as not only inducer, but also carbon source and nitrogen source. Furthermore, preliminary experiments indicated that chitinase production was significantly influenced by chitin. The high similarity between the observed value and the predicted ones showed that the RSM was an accurate and applicable tool to optimize culture medium for chitinase yield in Chitinolyticbacter meiyuanensis SYBC-H1 industry. By utilizing the statistical methodology, the optimum chitinase activity was determined to be 5.17 $\mathrm{U} / \mathrm{mL}$. Under optimized culture conditions, the chitinase activity was 15 -fold than that under the original culture conditions. In particular, the culture time was also decreased. Although chitinase activity slightly lower than Streptomyces (26), but it is low cost in substrate. To further increase the yield of chitinase, we will attempt to construct recombinant Chitinolyticbacter meiyuanensis SYBC-H1 using the molecular biotechnology. Further works will be continued in our studies.

\section{ACKNOWLEDGEMENTS}

This work was financially supported by the National High Technology and Development Program of China (863 Program, grant No. 2010AA101501), National Institutes of Health grant GM-33048, the scientific \& technological personnel service project of the ministry of science and technology (Grant No. 2009GJ10038), the national natural science foundation of China (Grant No. 21045007), special funds of science \& technology innovation of science and technology department of Jiangsu province (Grant No. BY2010117), and the Fundamental Research Funds for the Central Universities JUSRP21120.

\section{REFERENCES}

1. Adinarayana, K.; Ellaiah, P. (2002). Response surface optimization of the critical medium components for the production of alkaline protease by a newly isolated Bacillus sp. J. Pharm. Sci., 5, 272-278.

2. Bhushan, B.; Hoondal, G. S. (1998). Isolation, purification and properties of a thermostable chitinase from an alkalophilic Bacillus sp. BG-11. Biotechnol. Lett., 20, 157-159.

3. Boman, H. G. (1995). Peptide antibiotics and their role in innate immunity. Annu. Rev. lmmunol., 13, 61-92.

4. Cha, J. M.; Cheong, K. H.; Cha, W. S.; Choi, D. B.; Roh, S. H.; Kim, S. I. (2004). Optimal conditions for chitinase production by Serratia marcescens. Biotechnol. Bioprocess. Eng. 9, 297-302.

5. Chang, S. C.; Wang, J. T.; Vandamme, P.; Hwang, J. H.; Chang, P. S.; Chen, W. M. (2004). Chitinimonas taiwanensis gen. nov., sp. nov., a novel chitinolytic bacterium isolated from a freshwater pond for shrimp culture. Syst. appl. microbiol., 27, 43-49.

6. Chang, W. T.; Chen, Y. C.; Jao, C. L. (2007). Antifungal activity and enhancement of plant growth by Bacillus cereus grown on shellfish chitin wastes. Bioresource Technol., 98, 1224-1230.

7. Dahiya, N.; Tewari, R.; Hoondal, G. S. (2006). Biotechnological aspects 
of chitinolytic enzymes: a review. Appl. Microbiol. Biot., 71, 773-782.

8. Deshpande, M. V. (1986). Enzymatic degradation of chitin and biological application. J. Sci. Ind. Res. India., 45,

9. Elibol, M. (2004). Optimization of medium composition for actinorhodin production by Streptomyces coelicolor A3(2) with response surface methodology. Process Biochem., 39, 1057-1062.

10. Ergun, M.; Ferda Mutlu, S. (2000). Application of a statistical technique to the production of ethanol from sugar beet molasses by Saccharomyces cerevisiae. Process Biochem., 73, 251-255.

11. Flach, J.; Pilet, P. E.; Jolles, P. (1992). What's new in chitinase research? Experientia, 48, 701-716.

12. Fleuri, L. F.; Kawaguti, H. Y.; Sato, H. H. (2009). Production, purification and application of extracellular chitinase from Cellulosimicrobium cellulans 191. Braz. J. Microbiol., 40, 623.

13. Gaoqiang, L.; Xiaoling, W. (2007). Optimization of critical medium components using response surface methodology for biomass and extracellular polysaccharide production by Agaricus blazei. Appl. Microbiol. Biot., 74, 78-83.

14. Gheshlaghi, R.; Scharer, J. M.; M, M.-Y.; Douglas, P. L. (2005). Medium optimization for hen egg white lysozyme production by recombinant Aspergillus niger using statistical methods. Biotechnol. Bioeng., 90, 754-760.

15. Gillis, M.; Vandamme, P.; De Vos, P.; Swings, J.; Kersters, K. (2001). Bergey's Manual of Systematic Bacteriology. Boone, D. R. Castenholz, R. W. e. New York: Springerd. P. taxonomyIn.

16. Gooday, G. W. (1999). Chitin and chitinases. Birkh userd. P. Aggressive and defensive roles for chitinases. In: Jolle's, Muzzarelli, R.A.A. (Eds.).

17. Graham, L. S.; Sticklen, M. B. (1994). Plant chitinases. Can. J. Biochem. 72, 1057-1083.

18. Hobel, C. F. V.; Hreggvidsson, G. O.; Marteinsson, V.; BahraniMougeot, F.; Einarsson, J.; Kristjansson, J. (2005). Cloning, expression, and characterization of a highly thermostable family 18 chitinase from Rhodothermus marinus. Extremophiles, 9, 53-64.

19. Huang, X. Q.; Wang, Y. F.; Cui, Y. H.; Hua, X. (2010). Optimization of Antifungal Effect of Surfactin and Iturin to Penicillium notatum in Syrup of Peach by RSM. Int. J. Pept. Res. Ther., 16, 63-69.

20. Kalil, S.; Maugeri, F.; Rodrigues, M. (2000). Response surface analysis and simulation as a tool for bioprocess design and optimization. Process. Biochem., 35, 539-550.

21. Liu, C.; Liu, Y.; Liao, W.; Wen, Z.; Chen, S. (2003). Application of statistically-based experimental designs for the optimization of nisin production from whey. Biotechnol. Lett., 25, 877-882.

22. Ludwig, W.; Strunk, O.; Klugbauer, S.; Klugbauer, N.; Weizenegger, M.; Neumaier, J.; Bachleitner, M.; Schleifer, K. H. (1998). Bacterial phylogeny based on comparative sequence analysis. Electrophoresis, 19 , 554-568.

23. Miyashita, K.; Fujii, T.; Sawada, Y. (1991). Molecular cloning and characterization of chitinase gene from Streptomyces lividans. J. Microbiol., 137, 2065-2072.

24. Muzzarelli, R. (1999). Native, industrial and fossil chitins. In:Jolles $P$ and Muzzareli RAA (eds) Chitin and chitinases Birkhauser, Basel, pp 16

25. Nakamura, T.; Ogata, Y.; Hamada, S.; Ohta, K. (1996). Ethanol production from Jerusalem artichoke tubers by Aspergillus niger and Saccharomyces cerevisiae* 1. J. Ferm. Bioeng. 81, 564-566.

26. Narayana, K. J. P.; Vijayalakshmi, M. (2009). Chitinase Production by Streptomyces sp. Anu 6277. Braz. J. Microbiol., 40, 725-733.

27. Ooijkaas, L. P.; Wilkinson, E. C.; Tramper, J.; Buitelaar, R. M. (1999). Medium optimization for spore production of Coniothyrium minitans using statistically-based experimental designs. Biotechnol. Bioeng., 64, 92-100.

28. Rao, K. J.; Kim, C. H.; Rhee, S. K. (2004). Statistical optimization of medium for the production of recombinant hirudin from Saccharomyces cerevisiae using response surface methodology. Process Biochem., 35, 639-647.

29. Rojas-Avelizapa, L. I.; Cruz-Camarillo, R.; Guerrero, M. I.; RodriguezVazquez, R.; Ibarra, J. E. (1999). Selection and characterization of a proteo-chitinolytic strain of Bacillus thuringiensis, able to grow in waste media. World J. Microb. Biot. 15, 261-268.

30. Sato, K.; Kato, Y.; Taguchi, G.; Nogawa, M.; Yokota, A.; Shimosaka, M. (2009). Chitiniphilus shinanonensis gen. nov., sp nov., a novel chitindegrading bacterium belonging to Betaproteobacteria. J. Gen. Appl. Microbiol., 55, 147-153.

31. Singh, A. K.; Mehta, G.; Chhatpar, H. S. (2009). Optimization of medium constituents for improved chitinase production by Paenibacillus sp. D1 using statistical approach. lett. Appl. microbiol., 49, 708-714.

32. Treichel, H.; Oliveira, D.; Mazutti, M. A.; Di Luccio, M.; Oliveira, J. V. (2010). A Review on Microbial Lipases Production. Food Bioprocess Tech., 3, 182-196.

33. Vaidya, R. J.; Shah, I. M.; Vyas, P. R.; Chhatpar, H. S. (2001). Production of chitinase and its optimization from a novel isolate Alcaligenes xylosoxydans: potential in antifungal biocontrol. World $J$. Microb. Biot., 17, 691-696.

34. Wang, S. L.; Lin, T. Y.; Yen, Y. H.; Liao, H. F.; Chen, Y. J. (2006). Bioconversion of shellfish chitin wastes for the production of Bacillus subtilis W-118 chitinase. Carbohydr. Res., 341, 2507-2515.

35. Wasli, A. S.; Salleh, M. M.; Abd-Aziz, S.; Hassan, O.; Mahadi, N. M. (2009). Medium Optimization for Chitinase Production from Trichoderma virens using Central Composite Design. Biotechnol. Bioprocess. Eng., 14, 781-787.

36. Yu, X.; Hallet, S. G.; Sheppard, J.; Watson, A. K. (1997). Application of the Plackett-Burman experimental design to evaluate nutritional requirements for the production of Colletotrichum coccodes spores. Appl. Microbiol. Biot., 47, 301-305. 